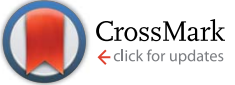

Cite this: RSC Adv., 2017, 7, 5466

Received 27th November 2016 Accepted 12th January 2017

DOI: 10.1039/c6ra27409a

www.rsc.org/advances

\title{
Phytate extraction from coproducts of the dry-grind corn ethanol process
}

\author{
Qiyang $\mathrm{He}^{\mathrm{ab}}$ Cristiano E. Rodrigues Reis, ${ }^{\mathrm{b}}$ Fei Wang ${ }^{\mathrm{a}}$ and Bo $\mathrm{Hu}^{\star \mathrm{b}}$
}

Distiller's dried grains with solubles (DDGS), the major coproduct of dry-grind ethanol production, are being increasingly used in the global market as animal feeds for both energy and protein supplement. DDGS contains high levels of phosphorus in the form of phytate, which cannot be digested by monogastric animals, such as poultry and swines, which in turn produce manure with high levels of phosphorus. Phytate is a highly-valued chemical and can be recovered from DDGS precursors in the downstream processing of dry-grind coproducts. This study was aimed at the utilization of the AG 1-X8 anion exchange resin to remove and purify phytates from thin stillage, and near $100 \%$ efficiency of adsorption and over $90 \%$ desorption from the resin beads was achieved. The end product showed a similar profile to the standard phytate, and could be precipitated and crystallized as calcium phytate. This process may potentially bring benefits to the parties involved, more revenue to corn ethanol facilities, improved digestibility of animal feeds, and minimized environmental impact, as less manure with a high content of phosphorus is applied to the soil.

\section{Introduction}

With the recent expansion of the U.S. corn ethanol industry and fluctuations in the corn and ethanol markets, the coproducts generated from ethanol separation processes are playing a vital role in the overall economic turnout of corn ethanol facilities and are saturating the global markets with feeds for energy and protein replacement. ${ }^{1}$ In a typical dry-grind processing, corn is directly milled without soaking in water and then enzymes and yeast are sequentially added for the ethanol fermentation. ${ }^{2}$ This process is characterized for its high versatility and low capital investment. The fermentation broth is then processed by distillation, such that ethanol is separated and the residue is the whole stillage (WS). WS is composed of proteins, fibers, residual sugars, lipids, and other minor components, derived from both the yeast cells and unfermented corn residues. ${ }^{3} \mathrm{WS}$ is centrifuged and separated into two streams: thin stillage (TS), a liquid phase with over $90 \%$ of moisture content, and wet distillers grains (WDG), which is the heavy fraction, with a solid content of around 50\%. Throughout the several possible procedures found in industrial plants, TS is usually evaporated and concentrated to achieve a lower moisture content, producing industrial "syrup", often labelled as condensed distillers with solubles (CDS). This syrup is then mixed with the solids present from WDG, and then dried at high temperatures to generate distiller's dried grains with

${ }^{a}$ College of Chemical Engineering, Nanjing Forestry University, Jiangsu Key Lab of Biomass-Based Green Fuels and Chemicals, Nanjing, Jiangsu, 210037, China

${ }^{b}$ Department of Bioproducts and Biosystems Engineering, University of Minnesota, 316 Biological and Agricultural Engineering, 1390 Eckles Ave, Saint Paul, MN, 55108-6005, USA.E-mail: bhu@umn.edu; Fax: +1-612-624-3005 solubles (DDGS). ${ }^{4}$ In order to increase the shelf life of DDGS for commercialization, the drying process of DDGS is crucial. During the pre-processing of the corn grains the dry-grind process is conducted by physical methods such as hammering, and thus the generated coproducts usually contain detectable levels of starch and impurities. ${ }^{5}$ There are often additives in this process, such as enzymes and vitamins, which can increase the overall nutritional value of DDGS. ${ }^{6}$

There has been a growth in the production and commercialization of DDGS due to the rapid expansion of the dry-grind process throughout the ethanol industry. Due to the nutritional value present in DDGS, it quickly gained attention from the markets and in 2015 achieved a significant share, about $23 \%$, of the non-ruminant animal feeding markets, such as poultry and swine industries. ${ }^{7}$ DDGSs are also an important source of minerals and are known as a feeding material rich in potassium, magnesium, zinc, sulfur, and phosphorus $(\mathrm{P}) .{ }^{\mathbf{8} 9}$ As regards to $\mathrm{P}$, this nutrient is often regarded as one of the most economic value components in animal feeds. However, Spiehs et $a .^{\mathbf{1 0}}$ reported too high levels of $\mathrm{P}$ in DDGS, with concentrations as high as $10 \mathrm{~g}$ of $\mathrm{P}$ per $\mathrm{kg}$ on dry basis. Such concentration is higher than the requirements of most ruminant animals. ${ }^{6}$ In DDGS, the largest portion of organic $P$ is found as phytate. This molecule cannot be directly assimilated by non-ruminant animals due to the lack of microbial phytases in their digestive system. ${ }^{11}$ Feeding non-ruminants with phytate-rich materials, such as DDGS, will further increase the $\mathrm{P}$ content in manures, which are often applied as fertilizers by farmers. ${ }^{\mathbf{1 0}}$ These high levels of $\mathrm{P}$ in soil typically exceed the soil binding capacity for phosphates and other forms of $\mathrm{P}$ ions, potentially 
resulting in high levels of $\mathrm{P}$ in runoff water. The major environmental impact of such an effect is the eutrophication of surface and underground water bodies. ${ }^{6,12,13}$

In corn, $\mathrm{P}$ is mostly present as inositol-phosphates. ${ }^{14}$ One molecule of inositol can bind up to six phosphate anions. The fully substituted molecule, inositol-hexaphosphate (IP6), is often referred as phytic acid, or known by its salt name, phytate. According to Ravindran et al. ${ }^{15}$ phytate is present in levels ranging from $50 \%$ to $80 \%$ of the total $\mathrm{P}$ present in corn. Phillippy et $a l .{ }^{16}$ evaluated the potential of industrial yeasts for hydrolyzing phytate during ethanol fermentation, and reported that these cells are able to produce phytase. This enzyme is able to degrade phytate to the forms of inositol mono-, bis-, tris-, tetra-, and pentakisphosphates (IP1, IP2, IP3, IP4, and IP5), as well as inorganic phosphate. The global market for phytase has grown significantly over the past years, resolving specific demands for monogastric animals, and its market value reached over 700 million US dollars in 2015. ${ }^{17}$ However, according to $\mathrm{Liu}$ and $\mathrm{Han},{ }^{3}$ in corn-to-ethanol fermentation systems without exogenous phytase addition, about $40 \%$ to $50 \%$ of $\mathrm{P}$ in the fermentation mash usually remains as phytate.

Several attempts to increase the degradation of phytate throughout or after the fermentation have been recently reported in the literature. Noureddini and Dang ${ }^{18}$ added phytase from Aspergillus niger to catalyze phytate hydrolysis in WS, whereas Khullar et $a .^{19}$ proposed a step of incubation with phytase prior to corn saccharification. Despite the environmental problems posed with phytates in the corn ethanol industry, this molecule is often seen as a high-value chemical in the market. Highly employed by some sectors of the food market and textile industries, phytate exhibits strong chelating and preservative properties, ${ }^{\mathbf{2 0 , 2 1}}$ and an excellent inoxidizability, ${ }^{22}$ being often used as food additive, preservative, and antioxidant. In recent years, the beneficial effects of phytates have been highlighted and explored by the pharmaceutical industry, particularly in the prevention of renal calculi, ${ }^{23}$ diabetes, ${ }^{24}$ some types of cancer, ${ }^{25}$ and Parkinson's disease. ${ }^{26}$

If phytate could be extracted from DDGS, it will be a win-win situation for both the industrial sector and environmental protection. The industrial process for phytate manufacturing consists of acid extraction from rice bran or cereals, followed by a chemical precipitation step. Strong acids are needed to dissolve phytates in a traditional phytate extraction. ${ }^{27}$ If phytate was to be recovered from end products, such as DDGS, the low $\mathrm{pH}$ of the extracted product would likely make it inappropriate as a feeding material. Ion exchange techniques have been applied to extract $\mathrm{P}$ products from liquids. ${ }^{28-30}$ However, little has been done on phytate extraction from corn ethanol coproducts. This study assayed a particular type of anionic resin, AG 1-X8, and the critical operational conditions to maximize phytate extraction from dry-grind coproducts.

\section{Materials and methods}

\section{Sample collection, storage and chemicals}

WS, TS, WDG, CDS, and DDGS were obtained from a large-scale dry-grind corn ethanol plant located in the state of Iowa, USA.
All samples were stored in the refrigerator at $-20{ }^{\circ} \mathrm{C}$ prior to use. The AG 1-X8 anion exchange resin (100-200 mesh, chloride form) was purchased from Bio-Rad Co. (Berkeley, CA). All the other chemicals were of analytical grade.

\section{Sample analysis and preparation}

All samples were analyzed for moisture content (wet basis), total P, and phytate $\mathrm{P}$. Moisture content was defined as the ratio between the weight loss after drying at $105^{\circ} \mathrm{C}$ and the wet weight. For total $\mathrm{P}$ determination, samples were dry-ashed, and the colorimetric assay for $\mathrm{P}$ was performed in the digests. The samples were analyzed with an adapted molybdate-blue method, based on P test kits (Hach, Loveland, CO). An acid extraction with $1 \mathrm{~mol} \mathrm{~L}^{-1} \mathrm{HCl}$ was performed prior to phytate analysis. In order to precipitate the $\mathrm{P}$ salts, the $\mathrm{pH}$ of the liquid phases, containing soluble phytates, was changed to neutral by treatment with $1 \mathrm{~mol} \mathrm{~L}^{-1} \mathrm{CaCl}_{2}$ solution. $\mathrm{P}$ salt sediments were then washed, dried and redissolved in $1 \mathrm{~mol} \mathrm{~L}^{-1} \mathrm{HCl}$, for which analysis on total $\mathrm{P}$ and phosphate $\mathrm{P}$ by the molybdate-blue method were conducted. Phytate $\mathrm{P}$ content was defined as the difference between total P and phosphate P. All chemical analyses were conducted in triplicate.

\section{Batch extraction: adsorption and desorption}

The AG 1-X8 resin was equilibrated with $2 \mathrm{~mol} \mathrm{~L}^{-1} \mathrm{HCl}$, and then washed with distilled water, promoting the $\mathrm{pH}$ change to neutral. Then, $10 \mathrm{~mL}$ of CDS or TS solution were added to a 25 $\mathrm{mL}$ glass vial containing $3 \mathrm{~g}$ of the resin. Adsorption efficiency was defined as the ratio between the $\mathrm{P}$ concentration in the supernatant and the initial $\mathrm{P}$ concentration in the liquid phase. Throughout full factorial experimental design, effect of time, temperature, and $\mathrm{pH}$ on adsorption were investigated.

For evaluating desorption, the resin beads were removed by filtration and added to various eluent solutions at different concentrations. These eluents $(\mathrm{HCl}, \mathrm{NaOH}$, and $\mathrm{NaCl})$ were intended to elute the retained $\mathrm{P}$ anions from the resin beads. Desorption efficiency was calculated as the ratio between $\mathrm{P}$ concentration in the supernatant and total $\mathrm{P}$ amount adsorbed on the resin beads.

\section{Column extraction - adsorption and desorption}

A chromatographic glass column $(1.0 \mathrm{~cm} \times 30 \mathrm{~cm})$ was used as support for the AG 1-X8 resin. The resin beads, loaded at different weights, were equilibrated with $\mathrm{HCl} 2 \mathrm{~mol} \mathrm{~L}^{-1}$ and washed with distilled water until the $\mathrm{pH}$ in the eluted water was neutral. The liquid phase of TS was used as the target solution, which was added sequentially with a loading increment of 10 $\mathrm{mL}$, i.e., each $10 \mathrm{~mL}$ of solution added and adsorbed was analyzed in terms of reduction of the $\mathrm{P}$ level. Prior to desorption, the resin beads were washed with distilled water for removal of impurities.

For the desorption experiments, the desorption agent solution was loaded sequentially in volumes of $10 \mathrm{~mL}$, i.e., each 10 $\mathrm{mL}$ of solution added was analyzed in terms of concentration of $\mathrm{P}$ compound. Desorption efficiency was defined as the increment in $\mathrm{P}$ concentration over the amount of $\mathrm{P}$ adsorbed on the resin beads. 
Calcium phytate precipitation and attenuated total reflection Fourier transform infrared spectroscopy (ATR-FTIR) analysis

Phytate precipitation was carried out by adding excess $\mathrm{Ca}^{2+}$, as $\mathrm{CaCl}_{2}$, followed by a pH shift to neutral by the addition of $\mathrm{NaOH}$. The obtained sediments were washed with distilled water and dried at $105{ }^{\circ} \mathrm{C}$ until constant weight was obtained.

For the ATR-FTIR analysis, spectra were recorded in the 4000 to $400 \mathrm{~cm}^{-1}$ range on a Thermo Scientific Nicolet iS50 FTIR spectrometer (Waltham, MA) with a built-in diamond ATR. The background used was ambient air. Each test was scanned 32 times with a resolution of $0.24 \mathrm{~cm}^{-1}$. All spectra were normalized. Sodium phytate hydrate from rice (S06880/Pfaltz \& Bauer, Waterbury, CT) was used as standard. Sodium phytate samples were obtained using $\mathrm{NaCl}$ as the eluting agent, followed by evaporating this solution at $40{ }^{\circ} \mathrm{C}$.

\section{Results and discussion}

\section{Moisture content and $P$ analysis}

The WS, containing undissolved corn fragments and residual yeast cells, presented a moisture content of $87.94 \%$. During solid-liquid separation of WS, most solids in WS are redirected to WDG. TS had a moisture content of $95.71 \%$, whereas WDG had $49.75 \%$. In CDS, concentrated from TS through series of evaporations, a moisture content of $70.48 \%$ was achieved. CDS has a viscous texture, and moisture contents lower than $70 \%$ are economically unfeasible, ${ }^{9}$ mainly due to the increase in suspended solids and osmotic pressure. The dry blend of CDS and WDG was dried to produce DDGS. DDGS samples used in this study presented moisture contents of about $14.92 \%$, within the expected range reported to prevent DDGS from becoming moldy and unusable. ${ }^{31}$

WS had a total $\mathrm{P}$ concentration of $12.02 \mathrm{mg} \mathrm{g}^{-1}$, of which $40 \%$ was found to be phytate $\mathrm{P}$, with a concentration of $4.81 \mathrm{mg}$ $\mathrm{g}^{-1}$. After the first solid-liquid separation, the concentrations of total $\mathrm{P}$ and phytate $\mathrm{P}\left(23.57 \mathrm{mg} \mathrm{g}^{-1}\right.$ and $10.11 \mathrm{mg} \mathrm{g}^{-1}$, respectively) in the TS had doubled, whereas WDG presented much lower concentrations of total $\mathrm{P}$ and phytate $\mathrm{P}\left(10.21 \mathrm{mg} \mathrm{g}^{-1}\right.$ and $3.27 \mathrm{mg} \mathrm{g}^{-1}$, respectively). The difference was most likely attributed to the fact that more $\mathrm{P}$ went to the liquid phase (TS) than the solid phase (WDG) during the solid-liquid separation of WS, which primarily indicates that most $\mathrm{P}$ in the streams is soluble. $^{3}$ The water removal step on TS to produce CDS maintained similar levels of total $\mathrm{P}\left(23.77 \mathrm{mg} \mathrm{g}^{-1}\right)$ and showed a slight decrease of phytate $\mathrm{P}\left(9.41 \mathrm{mg} \mathrm{g}^{-1}\right)$. Due to the recycling of a TS portion as a backset for the cooking step, the concentrations of both total $\mathrm{P}$ and phytate $\mathrm{P}$ in DDGS $\left(10.59 \mathrm{mg} \mathrm{g}^{-1}\right.$ and $4.50 \mathrm{mg} \mathrm{g}^{-1}$, respectively) were just a little lower than those of WS. ${ }^{3}$ Comparing with the literature results, ${ }^{4}$ similar values were found, particularly for fractions of TS $\left(19.4 \mathrm{mg} \mathrm{g}^{-1}\right)$, CDS (18.8 $\mathrm{mg} \mathrm{g}^{-1}$ ), and WS (11.0 $\mathrm{mg} \mathrm{g}^{-1}$ ) in terms of total P. As shown in Table 1, TS was the stream with the highest moisture content in the downstream processing of dry-grind coproducts.

Corn grain presents high phytate levels, with as much as $90 \%$ of organic $\mathrm{P}$ found as phytate, ${ }^{32}$ representing overall levels of around $75 \%$ of the total $\mathrm{P}$ found in the kernel. ${ }^{33}$ Assuming
Table 1 Moisture content, total $\mathrm{P}$, and phytate $\mathrm{P}$ in dry-grind coproducts

\begin{tabular}{lllc}
\hline Sample & Moisture content $(\%)$ & Total $\mathrm{P}\left(\mathrm{mg} \mathrm{g}^{-1}\right)$ & Phytate $\mathrm{P}\left(\mathrm{mg} \mathrm{g}^{-1}\right)$ \\
\hline WS & $87.94 \pm 0.15$ & $12.02 \pm 0.60$ & $4.81 \pm 0.01$ \\
TS & $95.71 \pm 0.13$ & $23.57 \pm 1.12$ & $10.11 \pm 0.66$ \\
WDG & $49.75 \pm 0.40$ & $10.21 \pm 0.53$ & $3.27 \pm 0.21$ \\
CDS & $70.48 \pm 0.22$ & $23.77 \pm 0.23$ & $9.41 \pm 0.34$ \\
DDGS & $14.33 \pm 0.39$ & $10.59 \pm 0.20$ & $4.50 \pm 0.15$ \\
\hline
\end{tabular}

that the $\mathrm{P}$ present in corn is not a limiting factor in the ethanol fermentation, and thus, no extra $\mathrm{P}$ is added to the fermentation media, it is observed that phytate levels decrease when comparing ethanol coproducts and corn. Andlid et al. ${ }^{34}$ attributed this to the expression of a type of phytase enzyme by Saccharomyces cerevisiae during the fermentation. We assumed that the combination of acidic $\mathrm{pH}$, high temperature during processing, and the presence of endogenous phytase in the fermentation tank favor the hydrolysis of the phytate present in corn. Even though phytate levels are decreased on a relative basis, Liu and $\mathrm{Han}^{3}$ described several-fold increase in nutrients during the downstream processing of dry-grind ethanol plants. Thus, phytate, even though is degraded during fermentation, is still found at relative large concentrations due to nutrient increase, as described by Liu and Han. ${ }^{3}$

\section{Evaluation of phytate extractants}

Experiments of phytate extraction with acid or water (Fig. 1) show that phytate concentrations in acid and water extracts from CDS differed by only $6.2 \%\left(1026 \mathrm{mg} \mathrm{L}^{-1}\right.$ for the acid extract, and $966 \mathrm{mg} \mathrm{L}^{-1}$ for the water extract), with a significance level of 0.06 . Similar results were reported, with $82 \%$ of the total $\mathrm{P}$ in WS dissolved in the liquid phase. ${ }^{13}$ Since the majority of phytates in the streams were present as the soluble form, the extraction with strong acids, which brings additional cost and damage to the raw material and barely provides any significant process gain, could be avoided. Thus, the feeding value of the coproducts could be maintained by introducing a mild extraction method.

Latta and Eskin, ${ }^{35}$ and Haug and Lantzsch ${ }^{36}$ have developed extraction methods for phytate in cereals. Their methods

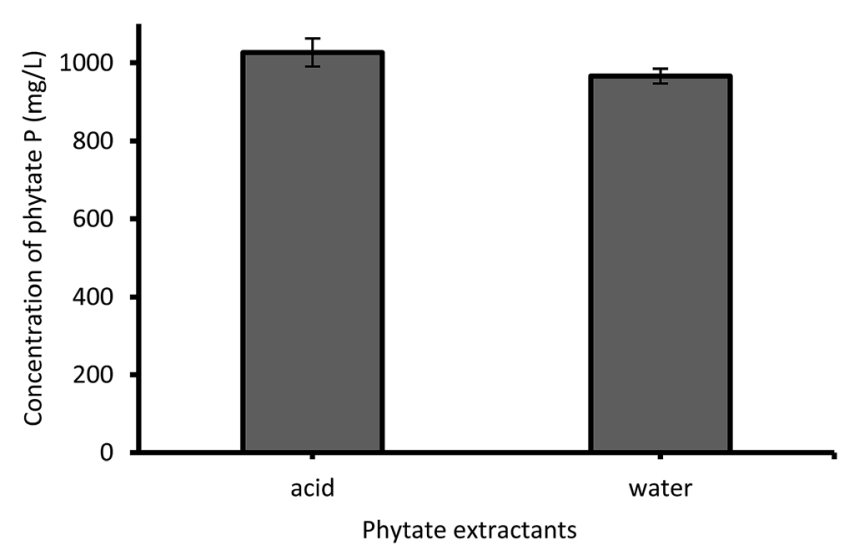

Fig. 1 Phytate extraction from CDS by different extractants. 
include an acid pretreatment of phytate-rich grains, using dilute $\mathrm{HCl}$, which has proven to dissolve the phytate present in granules into the bulk solution phase. The results of this study showed that most phytate may have already been dissolved in the liquid fraction due to the low $\mathrm{pH}$ (4.42) of CDS. In addition, the $\mathrm{pH}$ of TS and WS were 4.47 and 4.48 , respectively, which meant phytate in TS and WS were likely to be present in its soluble form, as evidenced from the significant increase in concentration of this substance in the liquid phase (TS).

\section{Effect of moisture content on the batch extraction of phytate by anion exchange}

Batch extraction of phytate from CDS at different dilutions (Table 2) showed significant variability among samples with different moisture contents ( $p$-value $<0.05$ for total $\mathrm{P}$ and phosphate). Controlling the moisture content of CDS by water addition reflected the concentration of $\mathrm{P}$ in the samples. Resin AG 1-X8 showed a better adsorption performance on P solutions with lower concentrations, achieving a $64.51 \%$ adsorption of the total $\mathrm{P}$ at a moisture content of $95 \%$, whereas only $43.92 \%$ of the total P was adsorbed at a moisture content of $75 \%$. Solidliquid adsorption occurs in four steps: liquid phase mass transfer, interface diffusion between the liquid phase and the exterior surface of the adsorbent, intrapellet mass transfer involving pore diffusion and surface diffusion, and an adsorption-desorption reaction. The increase in viscosity and osmotic pressure effects followed by a decrease in moisture content is hypothesized to be a key factor in the liquid phase mass transfer and on the pore diffusion and surface diffusion processes involved in ion exchange.

Table 2 Effect of moisture content, temperature, time, and $\mathrm{pH}$ on $\mathrm{P}$ adsorption

\begin{tabular}{|c|c|c|c|}
\hline \multirow[b]{2}{*}{ Factor } & \multirow[b]{2}{*}{ Level } & \multicolumn{2}{|c|}{ Adsorption efficiency (\%) } \\
\hline & & Phosphate & Total P \\
\hline \multirow[t]{5}{*}{ Moisture content of CDS (\%) } & 95 & 50.70 & 64.51 \\
\hline & 90 & 46.42 & 59.13 \\
\hline & 85 & 37.70 & 54.47 \\
\hline & 80 & 33.83 & 49.85 \\
\hline & 75 & 31.43 & 43.92 \\
\hline \multirow[t]{5}{*}{ Temperature $\left({ }^{\circ} \mathrm{C}\right)$} & 4 & 34.83 & 62.65 \\
\hline & 30 & 38.86 & 64.26 \\
\hline & 40 & 39.53 & 63.02 \\
\hline & 50 & 39.32 & 63.68 \\
\hline & 60 & 38.68 & 63.24 \\
\hline \multirow[t]{6}{*}{ Time (min) } & 10 & 38.68 & 64.26 \\
\hline & 20 & 39.53 & 64.49 \\
\hline & 30 & 38.89 & 64.39 \\
\hline & 60 & 40.17 & 64.19 \\
\hline & 120 & 38.98 & 64.42 \\
\hline & 1440 & 39.53 & 63.97 \\
\hline \multirow[t]{6}{*}{$\mathrm{pH}$} & 1 & 22.85 & 47.01 \\
\hline & 2 & 28.39 & 57.29 \\
\hline & 3 & 31.73 & 59.26 \\
\hline & 4 & 33.54 & 63.09 \\
\hline & 5 & 35.27 & 64.19 \\
\hline & 6 & 39.92 & 64.17 \\
\hline
\end{tabular}

The highest adsorption efficiency of phosphate and total P was attained on diluted CDS with 95\% moisture content, which was very close to that of TS $(95.71 \%)$. In this process, approximately $75 \%$ of the total $\mathrm{P}$ flows into TS after centrifugation of WS. ${ }^{4}$ If most phytate in TS could be extracted, the final content of phytate in DDGS would be drastically decreased. Furthermore, due to the composition of TS, most residual solids, which are dead yeast cells and small corn residue particles, ${ }^{37}$ can be separated by a simple filtration, centrifugation or decantation. Therefore, subsequent extraction experiments were focused on TS.

\section{Effect of temperature and time on the batch extraction of phytate by anion exchange}

The adsorption efficiency for TS, an extract with high concentrations of total P, presented a constant value of $63.4 \%$ for total $\mathrm{P}$ ( $p$-value $<0.01)$ and a desirable lower efficiency of $38.1 \%$ for phosphate ( $p$-value $<0.05$ ), across the range of temperatures studied, as shown in Table 2. The robustness of this resin, under the conditions studied, is highly desirable for P extraction because, according to Lee et al. ${ }^{38}$ processing of TS in a drygrind ethanol plant occurs within a narrow range of temperatures close to $70{ }^{\circ} \mathrm{C}$.

The results for adsorption potential were constant at the time range studied (Table 2), from $10 \mathrm{~min}$ to $1440 \mathrm{~min}$, achieving a constant value of $64 \%$ ( $p$-value $<0.05)$. These results may suggest that the adsorption equilibrium occurred within $10 \mathrm{~min}$ at the conditions studied. Previous chromatographic separations of phytate using similar types of resins and conditions achieved good separation of phytate within 30 minutes (ref. 35) or even with a separation column without control of residence time. ${ }^{36}$ The high moisture content and the amount of resin in contact with the bulk suspension of stillage allow a high adsorption rate, as predicted by Latta and Eskin. ${ }^{35}$

\section{Effect of $\mathrm{pH}$ on the batch extraction of phytate by anion exchange}

The results at the bottom of Table 2 showed better adsorption for both total $\mathrm{P}$ and phosphate at higher $\mathrm{pH}$ values within the acidic region. At extremely acidic conditions, such as $\mathrm{pH} 1,2$, and 3, total $\mathrm{P}$ was adsorbed at $47.01 \%, 57.29 \%$, and $59.26 \%$, respectively. Similar to phosphate, the values were $22.85 \%$, $28.39 \%$, and $31.73 \%$. For $\mathrm{pH}$ values ranging from 4 to 6 , a plateau region was obtained for the adsorption of total $\mathrm{P}$, attaining a circa $63 \%$ adsorption on the resin beads. For phosphate, however, there was still an increase in the adsorption within this range with the increment of $\mathrm{pH}$, with values of $33.54 \%, 35.27 \%$, and $39.92 \%$ at $\mathrm{pH}$ values of 4,5 , and 6 , respectively. The highest $\mathrm{P}$ adsorption levels were achieved at higher $\mathrm{pH}$ values. Kaufman and Kleinberg ${ }^{39}$ claimed that one of the most important factors for adsorption in anionic resins was the solution anion electronegativity. Phytate has six protons with $\mathrm{p} K_{\mathrm{a}}$ values of 2.18 , two with $\mathrm{p} K_{\mathrm{a}}$ of 5.73 , and two with $\mathrm{p} K_{\mathrm{a}}$ equal to $9.21 .^{40}$ Therefore, a high $\mathrm{pH}$ will favor the ionization of phytate by dissociating $\mathrm{H}^{+}$from the hydroxyls, resulting in an increase of electronegativity in phytate, which in turn will 
increase the ability of phytate to participate in the anion exchange. ${ }^{39}$ However, the precipitation that occurs in TS when $\mathrm{pH}$ is over 7 would hinder the anion exchange. The resin presented a good adsorption performance when the $\mathrm{pH}$ was from 4 to 6 (Table 2). Since the pH of the TS (4.47) was within this range, no $\mathrm{pH}$ adjustment was needed before adsorption.

\section{Phytate desorption from the anion exchange resin}

$\mathrm{NaCl}$ exhibited a better desorption performance on adsorbed phytate at both 0.5 and $1.0 \mathrm{~mol} \mathrm{~L}^{-1}$ concentrations as compared to $\mathrm{HCl}$ and $\mathrm{NaOH}$ (Table 3 ).

Table 4 shows that the highest desorption efficiency for phytate was obtained when the concentration of $\mathrm{NaCl}$ was over $1.5 \mathrm{~mol} \mathrm{~L}^{-1}$. Thereby, $1.5 \mathrm{~mol} \mathrm{~L}^{-1} \mathrm{NaCl}$ was used as eluent in subsequent column phytate extraction experiments. This can be explained by the displacement of adsorbed phosphorus anions by chloride anions from the eluate solution. The better performance of $\mathrm{NaCl}$ as a desorption agent agrees with a previous methodology for phytate extraction from cereal grains, in which Latta and Eskin ${ }^{35}$ used $\mathrm{NaCl}$ to selectively desorb phytate over inorganic phosphate from a similar anion exchange system. Helfferich $^{\mathbf{4 1}}$ described that $\mathrm{NaCl}$ is preferably used as a desorption agent, or even regeneration agent in some conditions, due to its low-toxic potential and low cost.

\section{Column extraction}

The column extraction results shown in Fig. 2, demonstrate a higher adsorption rate for phytate $\mathrm{P}$ than that for phosphate

Table 3 Effect of various eluents with different concentrations on the desorption efficiency of $P$

\begin{tabular}{lllll}
\hline \multirow{5}{*}{$\begin{array}{l}\text { Desorption } \\
\text { agent }\end{array}$} & $\begin{array}{l}l \\
\text { Desorption efficiency }(\%) \\
\left(\mathrm{mol} \mathrm{L}^{-1}\right)\end{array}$ & Phosphate & Phytate & Total P \\
\hline $\mathrm{HCl}$ & 0.5 & 65.96 & 26.15 & 26.15 \\
& 1.0 & 69.96 & 45.39 & 46.24 \\
$\mathrm{NaCl}$ & 0.5 & 60.47 & 33.87 & 36.24 \\
& 1.0 & 75.00 & 83.69 & 77.33 \\
$\mathrm{NaOH}$ & 0.5 & 47.73 & 9.66 & 16.35 \\
& 1.0 & 69.40 & 35.55 & 37.34
\end{tabular}

Table 4 Effect of different $\mathrm{NaCl}$ concentrations on the desorption efficiency of $\mathrm{P}$

\begin{tabular}{llrr}
\hline \multirow{2}{*}{$\begin{array}{l}\text { NaCl concentration } \\
\left(\mathrm{mol} \mathrm{L}^{-1}\right)\end{array}$} & \multicolumn{2}{l}{ Desorption efficiency (\%) } \\
\cline { 2 - 4 } & Phosphate & Phytate & Total P \\
\hline 0.05 & 36.15 & 2.68 & 9.44 \\
0.10 & 48.97 & 3.09 & 12.43 \\
0.25 & 57.81 & 8.21 & 18.17 \\
0.50 & 60.47 & 33.87 & 36.24 \\
1.00 & 72.39 & 81.96 & 73.97 \\
1.50 & 83.98 & 98.52 & 88.26 \\
2.00 & 80.60 & 97.50 & 86.87
\end{tabular}

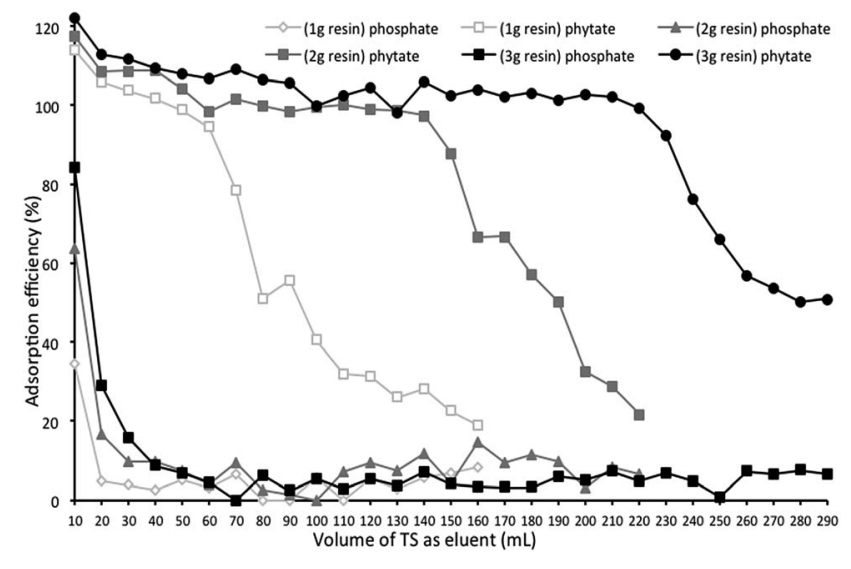

Fig. 2 Adsorption of phosphate and phytate during column extraction.

P. One of the most plausible theories could be the higher concentration of negatively charged oxygen atoms in phytate than in phosphate. ${ }^{39}$ The adsorption efficiency of phytate was sometimes over $100 \%$, and this excessive contribution was probably due to the presence of $\mathrm{P}$ in other forms being considered as phytate and also adsorbed on the resin. The scope of the adsorption curve shows a gradual decrease in the adsorption efficiency, explained by saturation of the resin beads with adsorbed ions. The results confirmed this theory since the higher the resin load, the higher the absolute saturation potential was determined to be. This increase might have resulted from the longer adsorption time caused by a higher amount of resin in the column.

For the column containing $3 \mathrm{~g}$ of AG 1-X8 resin, approximately $100 \%$ of total phytate and $6.15 \%$ of total phosphate in TS were adsorbed, using $220 \mathrm{~mL}$ of TS as elution agent. The results also showed a recovery of about $91 \%$ of adsorbed phytate using $1.5 \mathrm{~mol} \mathrm{~L}^{-1} \mathrm{NaCl}$ as the desorption agent, which had a total volume of $30 \mathrm{~mL}$ (Fig. 3). As a direct consequence of this, the eluate solution showed a significant increase in the concentration of phytate, when compared to its original concentration in the dry-grind coproducts. This increase in the

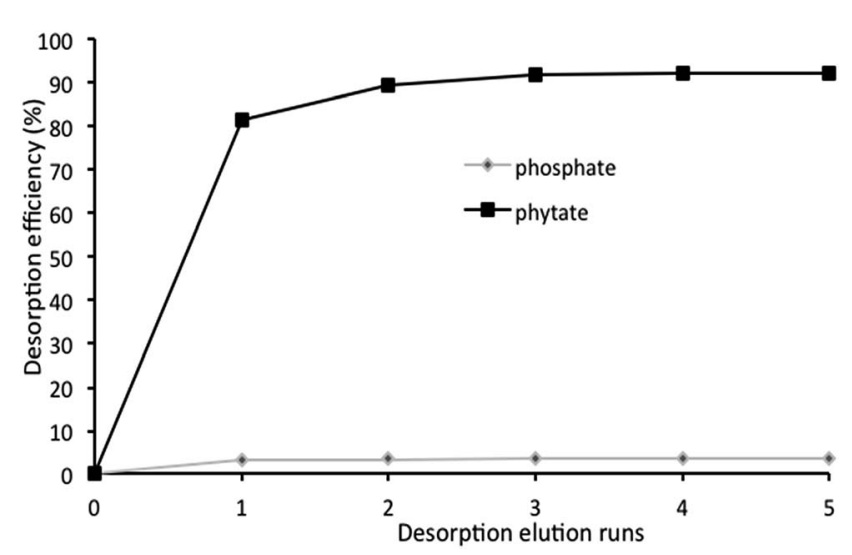

Fig. 3 Desorption of phosphate and phytate during column extraction. 
concentration could be conducive to harvest phytate via chemical precipitation.

\section{ATR-FTIR analysis of extracted phytate}

The ATR-FTIR spectra of standard sodium phytate and extracted sodium phytate are shown in Fig. 4. A weak absorption band around $1645 \mathrm{~cm}^{-1}$ and a broad absorption band at $3400 \mathrm{~cm}^{-1}$ (data not shown) were attributed to $\mathrm{O}-\mathrm{H}$ bonds of the adsorbed water molecules. ${ }^{42}$ The absorption band around $1398 \mathrm{~cm}^{-1}$ was assigned to the $\mathrm{C}-\mathrm{O}$ stretching vibration. ${ }^{43}$ Two bands around 1186 and $496 \mathrm{~cm}^{-1}$ are attributed to the $\mathrm{PO}_{4}{ }^{3-}$ groups. The bands around 1038, 986, 909, 850 and $793 \mathrm{~cm}^{-1}$ were ascribed to $\mathrm{C}-\mathrm{O}-\mathrm{P}$ vibrations from various types of phytate (IP2-IP6). ${ }^{44}$ The small shifts in the vibrational bands between the two types of sodium phytate were possibly due to the residual sodium chloride mixed in the extracted one and different types of phytate in the samples. ${ }^{43}$

\section{Overall yield and significance of the process}

Precipitation of phytate with $\mathrm{Ca}^{2+}$ ions does not only remove the chloride ions that are simultaneously desorbed, but also promotes the discoloration by the removal of some organic chromophoric molecules, which phytate could have adsorbed after the elution. From the results, $0.49 \mathrm{~g}$ of calcium phytate was yielded as a result of the first $30 \mathrm{~mL}$ elution. Based on the results, it was calculated that $0.39 \mathrm{~g}$ of $\mathrm{P}$ as pure phytate, or the equivalent of $1.85 \mathrm{~g}$ of calcium phytate, could be obtained from $1 \mathrm{~kg}$ of TS with the optimized conditions of this study.

The approach in this study provided a new method to remove phytate from the coproducts of the dry-grind corn ethanol process. It is expected that this extraction process will not have any significant negative effects on the nutritional value of DDGS as a whole since major nutrients cannot be adsorbed to the column under the conditions studied. For the dry-grind ethanol downstream processing, approximately $75 \%$ of the P present in WS is sent to TS. ${ }^{4}$ Thus, if most phytate in TS could be extracted, final content of $\mathrm{P}$ in DDGS would be drastically reduced. Removal of $\mathrm{P}$ from ethanol coproducts has been described

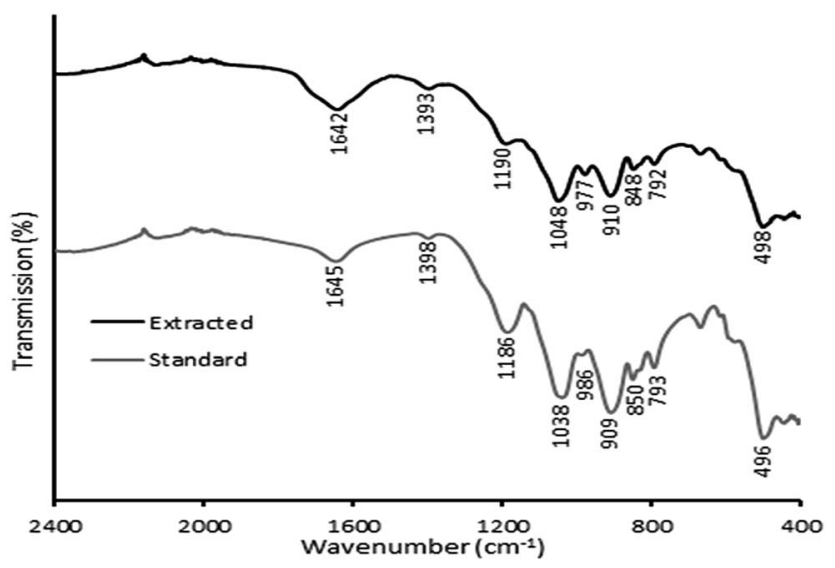

Fig. 4 FTIR spectra of sodium phytate from the extractions and standard sodium phytate from rice bran. before by Alkan-Ozkaynak et al., ${ }^{45}$ where they used aluminiumand calcium-based coagulants to recover $\mathrm{P}$ from TS through a chemical-based separation process, resulting in a sludge that could be applied to agriculture fields. This can provide a feasible solution to the P issue in DDGS, but little value is gained after the sludge is applied to the land. On the other hand, extraction of phytate and generation of calcium phytate can potentially yield additional revenue to the ethanol industry, as well as provide a solution to attenuate environmental concerns regarding the eutrophication of water bodies due to $\mathrm{P}$ runoff. Usually, $\mathrm{P}$ in soil after manure application moves to groundwater bodies and deep soil layers, potentially damaging the aquatic environment by eutrophication. ${ }^{46}$ This process may provide a great opportunity for the U.S. ethanol industry because extracting phytate from corn ethanol coproducts can create additional revenue while increasing the feeding value of coproducts and decreasing the $\mathrm{P}$ content in animal manure.

\section{Conclusion}

With this study, it was proved that it is better to start the extraction of phytate directly from TS since its acid treatment did not result in a significantly larger gain of phytate extraction. The AG 1-X8 resin was proved to be effective within the typical temperature range for TS processing, and the extraction could be accomplished within several minutes. Sodium chloride was proven to be the best desorption agent. Both the AG 1-X8 resin and $\mathrm{NaCl}$ have superior specificity for phytate adsorption and desorption over inorganic phosphate. The overall process could yield up to $1.85 \mathrm{~g}$ of calcium phytate per $\mathrm{kg}$ of TS.

\section{Acknowledgements}

This study was partially supported by grants from MnDrive Global Food Ventures and also partially supported by the Nanjing Forestry University (Priority Academic Program Development of Jiangsu Higher Education Institution). Reis's research is supported by CAPES, the Ministry of Education of Brazil, under grant number 13252/13-5.

\section{References}

1 K. Wang, L. Ou, T. Brown and R. C. Brown, Biofuels, Bioprod. Biorefin., 2015, 9, 190-200.

2 P. Luangthongkam, L. Fang, A. Noomhorm and B. Lamsal, Ind. Crops Prod., 2015, 77, 803-808.

3 K. Liu and J. Han, Bioresour. Technol., 2011, 102, 3110-3118.

4 A. Alkan-Ozkaynak and K. G. Karthikeyan, J. Environ. Qual., 2012, 41, 1695-1701.

5 H. Zabed, A. N. Boyce, J. N. Sahu and G. Faruq, J. Cleaner Prod., 2017, 142, 4282-4293.

6 K. D. Rausch and R. L. Belyea, Appl. Biochem. Biotechnol, 2006, 128, 47-86.

7 Renewable Fuels Association, Ethanol Industry Outlook, 2016, <http://ethanolrfa.org/resources/publications/outlook/ $>$.

8 A. Batal and N. Dale, J. Appl. Poult. Res., 2003, 12, 400-403. 
9 R. L. Belyea, T. E. Clevenger, V. Singh, M. E. Tumbleson and K. D. Rausch, Appl. Biochem. Biotechnol., 2006, 134, 113-128.

10 M. J. Spiehs, M. H. Whitney and G. C. Shurson, J. Anim. Sci., 2002, 80, 2639-2645.

11 G. L. Cromwell, R. D. Coffey, H. J. Monegue and J. H. Randolph, J. Anim. Sci., 1995, 73, 449-456.

12 R. Koelsch and G. Lesoing, J. Anim. Sci., 1999, 77, 63-71.

13 H. Noureddini, M. Malik, J. Byun and A. J. Ankeny, Bioresour. Technol., 2009, 100, 731-736.

14 N. R. Reddy, S. K. Sathe and D. K. Salunkhe, Adv. Food Res., 1982, 28, 1-92.

15 V. Ravindran, W. L. Bryden and E. T. Kornegay, Avian Poultry Biol Rev, 1995, 6, 125-143.

16 B. Q. Phillippy, K. D. White, M. R. Johnston, S. H. Tao and M. R. S. Fox, Anal. Biochem., 1987, 162, 115-121.

17 K. Bhavsar and J. M. Khire, RSC Adv., 2014, 4, 26677-26691. 18 H. Noureddini and J. Dang, Appl. Biochem. Biotechnol., 2009, 159, 11-23.

19 E. Khullar, J. K. Shetty, K. D. Rausch, M. E. Tumbleson and V. Singh, Cereal Chem., 2011, 88, 223-227.

20 R. Angel, N. M. Tamim, T. J. Applegate, A. S. Dhandu and L. E. Ellestad, J. Appl. Poult. Res., 2002, 11, 471-480.

21 A. Cupisti and K. Kalantar-Zadeh, Semin. Nephrol., 2013, 33, 180-190.

22 A. Marie Minihane and G. Rimbach, Int. J. Food Sci. Technol, 2002, 37, 741-748.

23 N. K. Saw, K. Chow, P. N. Rao and J. P. Kavanagh, J. Urol., 2007, 177, 2366-2370.

24 S.-H. Lee, H.-J. Park, H.-K. Chun, S.-Y. Cho, S.-M. Cho and H. S. Lillehoj, Nutr. Res., 2006, 26, 474-479.

25 I. Vucenik and A. M. Shamsuddin, Nutr. Cancer, 2006, 55, 109-125.

26 Q. Xu, A. G. Kanthasamy and M. B. Reddy, Toxicology, 2008, 245, 101-108.
27 C. Canan, F. T. L. Cruz, F. Delaroza, R. Casagrande, C. P. M. Sarmento, M. Shimokomaki and E. I. Ida, J. Food Compos. Anal., 2011, 24, 1057-1063.

28 J. Lehrfeld, Cereal Chem., 1989, 66, 510-515.

29 J. G. March, B. M. Simonet and F. Grases, J. Chromatogr. B: Biomed. Sci. Appl., 2001, 757, 247-255.

30 H.-R. Park, H.-J. Ahn, S.-H. Kim, C.-H. Lee, M.-W. Byun and G.-W. Lee, Food Control, 2006, 17, 727-732.

31 R. Bhadra, K. Muthukumarappan and K. A. Rosentrater, ASAE Paper, 2007, 1, 077009.

32 C. D. Boyer, J. C. Shannon, S. A. Watson and P. E. Ramstad, Corn: Chemistry and Technology, 1987, 253-272.

33 P. H. Abelson, Science, 1999, 283, 2015.

34 T. A. Andlid, J. Veide and A.-S. Sandberg, Int. J. Food Microbiol., 2004, 97, 157-169.

35 M. Latta and M. Eskin, J. Agric. Food Chem., 1980, 28, 13131315.

36 W. Haug and H. J. Lantzsch, J. Sci. Food Agric., 1983, 34, 1423-1426.

37 C. Liu, B. Hu, S. Chen and R. W. Glass, Appl. Biochem. Biotechnol., 2007, 137, 875-884.

38 P. H. Lee, J. Bae, J. Kim and W. H. Chen, J. Chem. Technol. Biotechnol., 2011, 86, 1514-1520.

39 H. W. Kaufman and I. Kleinberg, Arch. Oral Biol., 1970, 15, 917-934.

40 W. J. Evans, E. J. McCourtney and R. I. Shrager, J. Am. Oil Chem. Soc., 1982, 59, 189-191.

41 F. G. Helfferich, Ion Exchange, Courier Corporation, 1962.

42 L. Celi, S. Lamacchia, F. A. Marsan and E. Barberis, Soil Sci., 1999, 164, 574-585.

43 K. Ganesan and M. Epple, New J. Chem., 2008, 32, 1326-1330. 44 Z. He, C. W. Honeycutt, T. Zhang and P. M. Bertsch, J. Environ. Qual., 2006, 35, 1319-1328.

45 A. Alkan-Ozkaynak, K. G. Karthikeyan and A. Roa-Espinosa, Trans. ASABE, 2010, 53, 1287-1294.

46 X. Zhang, H. Lin and B. Hu, RSC Adv., 2016, 6, 57960-57968. 